\title{
USING A MULTIBEAM ECHOSOUNDER TO MONITOR AN ARTIFICIAL REEF
}

\author{
A.N. Tassetti ${ }^{\text {a, }}{ }^{*}$, S. Malaspina ${ }^{\text {a }}$, G. Fabi ${ }^{\text {a }}$
}

a National Council of Researches, Institute of Marine Sciences (CNR-ISMAR), L.go Fiera della Pesca, 60125, Ancona, Italy (nora.tassetti, silvia.malaspina, gianna.fabi)@an.ismar.cnr.it

\section{Commission V}

KEY WORDS: artificial reef, multibeam echosounder, bathymetry, scouring, seafloor mapping, bulk volume

\begin{abstract}
:
Artificial reefs (ARs) have become popular technological interventions in shallow water environments characterized by soft seabed for a wide number of purposes, from fisheries/environmental protection and enhancement to research and tourism.

AR deployment has the potential for causing significant hydrographical and biological changes in the receiving environments and, in turn, ARs are strongly affected by the surrounding area in terms of spatial arrangement and structural integrity as well as colonization by benthic communities and finfish.

In this context, ARs require a systematic monitoring program that a multibeam echosounder (MBES) can provide better than other sampling methods such as visual dives and ROV inspections that are not quantitative and often influenced by water visibility and diver experience/skills.

In this paper, some subsequent MBES surveys of the Senigallia scientifically-planned AR (Northern Adriatic Sea) are presented and state-of-the art data processing and visualization techniques are used to draw post-reef deployment comparisons and quantify the evolution of the reef in terms of spatial arrangement and bulk volume.

These multibeam surveys play a leading part in a general multi-year program, started simultaneously with the AR design and deployment and aimed to map how the reef structure quantitatively changes over time, as well as it affects the sea-bottom morphology and the fishery resource.

All the data, surveyed over years making use of different sampling methods such as visual and instrumental echosounding observations and catch rate surveys, gain a mechanistic and predictive understanding of how the Senigallia AR functions ecologically and physically across spatial and temporal scales during its design life.
\end{abstract}

\section{INTRODUCTION}

Artificial reefs (ARs) are widespread interventions of marine technology to mimic some functions of natural reefs such us protecting, regenerating and/or enhancing populations of living marine resources and habitats (Fabi et al, 2014).

ARs are deployed in coastal waters for different applications, from habitat/finfish protection and enhancement to coastal activity/conflict management. They are often planned to be multipurpose, joining together compatible functions such as protection and production.

AR deployment alters the physical and biological characteristics of the surrounding area, affect the sea-bottom morphology and cause long-term environmental changes such as variations in grain size distribution and sediment organic content due to the metabolic activity of benthic and fish assemblages associated to the reef.

In turn, movements and alterations, in terms of $\mathrm{AR}$ arrangement, dimension, shape and bulk volume can occur over time because of environmental and anthropic factors such as scouring, current, waves and sediment accumulation.

This, consequently, strongly affects the composition of the reef fish assemblage and the AR work itself.

Against this background, ARs require systematic monitoring programs that a multibeam echosounder (MBES) can provide better than other sampling methods such as visual dives and ROV inspections that are not quantitative and often influenced by water visibility and diver experience/skills.

Moreover, associating MBES data recorded along the water column, it is possible to map the behaviour, spatial distribution and abundance of fish inside/near the reef and so monitor the AR work during its time service life.

The use of multibeam sonars as tools for both bathymetric mapping and backscatter imaging is well established (Kenny at al., 2003, Brown et al., 2006).

Although shallow-water MBES has been widely used in mapping seabed morphology and composition (Beyer et al., 2005; Knaapen et al., 2005, Chakraborty et al., 2006, Mayer et al., 2006), pipeline routes (Paton et al., 1997, Ross et al., 2004), coral reefs (Conway et al., 2005, Roberts et al., 2005), wrecks (Lawrence et al., 2001, Mayer et al., 2003), mines and their extent of burial (Wolfon et al., 2007, Mayer et al., 2007), there is very scarce literature on its employment to monitor reef units or to investigate their horizontal/vertical movements and subsidence (Shyue et al., 1998, 2002).

Because of this, the key outline of this paper is to investigate the structural evolution of the Senigallia scientifically-planned AR on time using some subsequent Kongsberg EM3000S/EM3002S/EM3002D multibeam surveys..

These surveys are part of a long-term monitoring program, which started with the AR design and deployment in 1987 and included complementary techniques, gathering from visual and acoustic observations to monthly trammel net surveys, to assess the effectiveness of the reed as well as its environmental impacts and conflicts.

This monitoring program plays an instrumental role in generating a baseline of data to assist decision makers and researchers who have to evaluate AR function, test design choices (i.e. spatial arrangement, construction materials and location) and verify whether the reef is achieving or not its objectives.

\footnotetext{
* Corresponding author
} 


\section{MATERIALS AND METHODS}

\subsection{Senigallia AR}

2.1.1 Environmental conditions: Built-up about $2.3 \mathrm{~km}$ offshore from Senigallia along the western Adriatic coast (Figure 1) at an original depth of $11.2 \mathrm{~m}$, the reef is an open area exposed to two distinct NW-SE wind regimes and currents running parallel to the shoreline in the same direction. While the northwest Bora wind contributes to the intensification of a permanent south-eastward Adriatic current, southeast Scirocco wind induces a current reversal that is mainly driven by the horizontal density gradient with a direct connection between the intensity of the monthly current field at the study area and the spreading pattern of the fresh water from the Po River (Kovačević et al., 2000).

Wave heights are typically larger during early fall to winter mouths (November-February), averaging especially during last winters between 0.5 and $2 \mathrm{~m}$.

The AR site is characterized by a flat sand-muddy seabed and far from natural and artificial hard substrates. Poor underwater visibility is therefore very common because of current-induced suspensions of sand and mud, additional to important fluvial inputs from the Po and the local Cesano rivers.

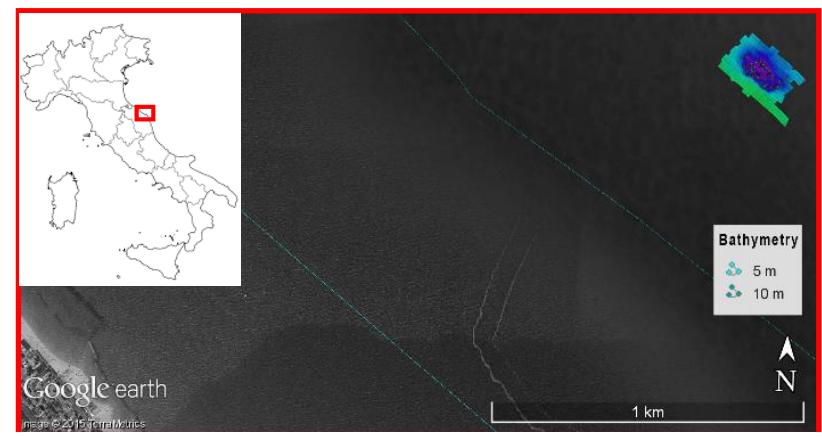

Figure 1. Study area location (Senigallia, Marche region, Italy)

2.1.2 Spatial arrangement: The Senigallia AR consists of 29 water-based 2-layer pyramids of 5 water-based cubic concrete block modules $(2 \times 2 \times 2 \mathrm{~m})$ and 12 water-based concrete cages $(6 \times 4 \times 5 \mathrm{~m})$ for shellfish culture, for a total volume of around $6.000 \mathrm{~m}^{3}$. Pyramids and cages were placed on gravel "mattresses" to spread the weight and prevent subsidence (Figure 2). Each block weights $13,000 \mathrm{~kg}$ and is characterized by rough surfaces to facilitate the settlement of benthic organisms and holes of different shape and size to provide habitats for marine biota.

The early schematic plan places pyramids following a $15 \times 15 \mathrm{~m}$ grid (Figure 3 ) and cages among the pyramids to give a structural continuity and increase the ecological functionality of the reef (Fabi et al., 1994, Bombace et al., 2000).
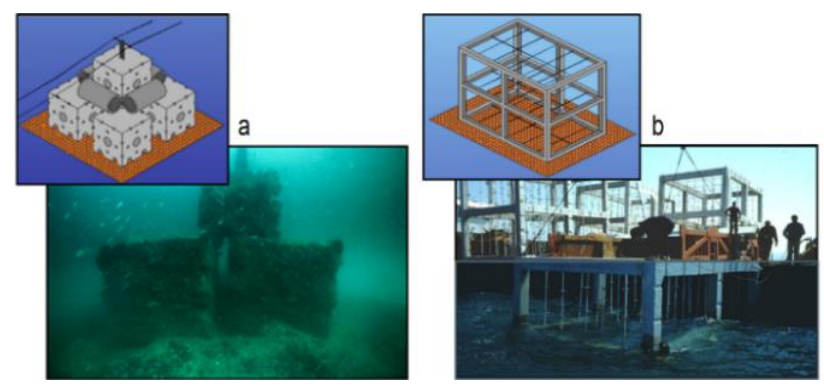

Figure 2. Two-layer pyramids of concrete blocks (a) and concrete cages for mussel culture (b)

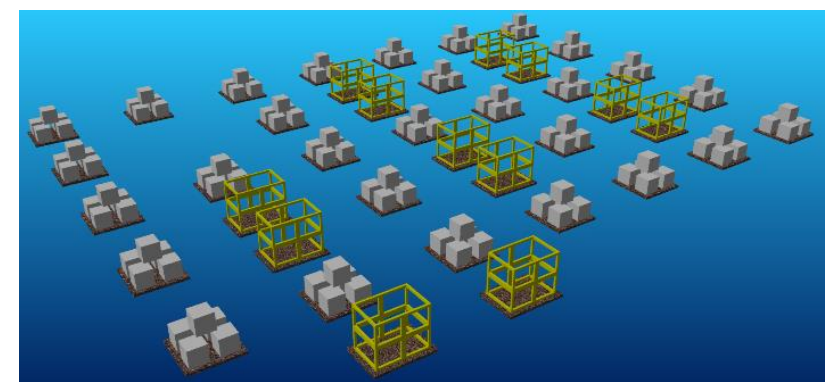

Figure 3. AR planned spatial arrangement

Additional cages/structures for lobster and fish repopulation were built later among the pyramids.

The position of the AR is indicated by a light signal placed on a fix pile which also hosts the marine station TeleSenigallia, transmitting near real time oceanographic and atmospheric data.

\subsection{Multi-year program mapping}

Since its deployment in 1987, the Senigallia AR has been systematically monitored by CNR-ISMAR (Ancona) employing differ techniques.

Originally, visual census was used to record a broad suite of information (i.e. AR status, fish abundance and habitat characteristics) with a frequency of once a year during the first five years after the reef was placed and of every two or three years thereafter (Bombace et al., 1997).

Later, with effect from 2001, Kongsberg Simrad EM3000/EM3002/EM3002D multibeam echo sounders have been employed giving metric information and providing a useful description of the local hydrodynamics and geological processes affecting the reef (Manukian et al., 2001, Manukian at al., 2011). Simultaneously in 2007 , biomass and vertical diel activity of fish assemblage has been evaluated, using traditional set-netting methods and enhanced stationary hydroacoustic techniques (Fabi et al., 2000, Sala et al., 2007) to investigate the distribution of the fish assemblage in relation to the arrangement and the structure state.

Over the last years, the monitoring program has been trimmed down.

It includes monthly trammel net surveys, carried out since January 1988, to detect/sample smaller assemblages inhabiting the reef and make comparisons with a reference area, selected about $2.5 \mathrm{~nm}$ far away to minimize possible influences of manmade substrates. They make up one of the longest trammel net data collection dealing with an AR in Europe.

MBES seafloor and water column surveys are staggered and, when possible, combined with underwater video/photographic sequencing to map every single AR structure and its structural integrity.

While this level of MBES performance is theoretically possible, to achieve it a careful data collection and processing is required in order to reduce instrumental and integration artefacts that could easily mask the scale of feature we are trying to map.

2.2.1 MBES data acquisition: High-resolution multibeam bathymetry data were collected to evaluate terrain changes around the structures, using Kongsberg Simrad Single head EM3000S up to 2006, EM3002S from 2006 to 2009 and Dual Head EM3002D Multibeam Echo Sounders since 2009, one after another mounted on research $\mathrm{M} / \mathrm{N}$ "Tecnopesca II" belonging to ISMAR - CNR of Ancona.

From 2001, the Konsberg Simrad EM3000 system allowed to map the seafloor using a $300 \mathrm{kHz}$ acoustic frequency and fanning 
out up to 127 acoustic beams at a maximum ping rate of $25 \mathrm{~Hz}$ and an angle of $130^{\circ}\left(1.5^{\circ} \times 1.5^{\circ}\right.$ beams are spaced $0.9^{\circ}$ apart $)$.

During the summer 2005, the Kongsberg Simrad EM3002 replaced the EM3000 system. Besides the technical and operational improvements, such as the increment up to 254 acoustic soundings at a maximum ping rate of $40 \mathrm{~Hz}$ and an angle of $130^{\circ}$, the EM3002 system extended the functionality of multibeam echo sounders to cover three-dimensional imaging of the water column. In fact, 164 acoustic beams are sampled digitally with a spatial resolution of $15 \mathrm{~cm}$ for each ping, creating a digital image of a slice of the water mass under the transducer. The nominal survey speed was kept at a steady $4 \mathrm{kn}$.

The high-repetition rate combined with the relatively slow survey speed assured a significant overlap of pings in the along-track direction while the $130^{\circ}$ swath width resulting in a coverage of 3.5 times water depth, assured a significant overlap in the acrosstrack direction.

Each MBES survey consisted of parallel transects, spaced $20 \mathrm{~m}$ apart, in order to assure a $100 \%$ coverage of the area. Six additional transects (3 perpendicular and 3 crossing) were surveyed to avoid false soundings and have a good resolution (Figure 6a).

Since 2014 the bottom survey has been associated to the water column survey. Sound speed profiles were collected at the start of the survey using a Smart SV\&P conductivity-temperaturedepth sensor.

The position of the boat was obtained via a 24-hour DGPS connected to a geostationary satellite, an Anshutz Standard 20 gyrocompass and a sound velocimeter.

With differential GPS, the system was capable of $\mathrm{cm}$ resolution with a depth accuracy of 10-15 cm RMS and a horizontal positional accuracy of less than $1 \mathrm{~m}$.

On board Kongsberg Simrad SIS software assisted in running the surveys efficiently, water column logging and real time data cleaning of bathymetric data or better automatic flagging of soundings which should be eliminated from the surveys. Seven surveys were carried out from 2001 up to 2014.

\subsubsection{MBES data processing:}

All multibeam data were cleaned and processed using CARIS HIPS and SIPS 8.1 software and QPS Fledermaus 7.4.2a.

Post-processing steps included editing, cleaning and resolving position and vessel attitude problems. Tidal correction were applied to the depth soundings using verified tide data, downloaded from the Ancona tidegauge station.

Within CARIS, the CUBE (Combined Uncertainty and Bathymetry Estimator) surface was used a cleaning tool and for product gridded surface creation.

During the CUBE surface creation, soundings were weighted and contributed to surface grid nodes based on TPU (Total Propagated Uncertainty) values and distance from the nodes. CUBE decisions were verified and sometimes overridden to model the actual seafloor and ensure to have the shoalest soundings (i.e. AR edges) honoured in all the final bathymetric products.

Because of the presence of fish assemblages, the water column data was often used to perform quality control on the bathymetry as well as, especially dealing with the marine station piling (Figure 4), to pick returns for adding as additional bathymetry.

The MBES high lateral resolution, the acquisition plan and the small extent of the studied area justified gridding with a pixel of $15-25 \mathrm{~cm}$. Where the $15-\mathrm{cm}$ grid resolution was too small to provide full coverage in areas of sparse data, the grids were interpolated to fill data gaps $(3 \times 3$-grid node area with a threshold level of 6 neighbours).

Gridded data sets were rendered into 3-D images and interactively explored using Fledermaus software.
The produced MBES bathymetric maps of the Senigallia AR allowed to evidence any alteration incurred in the artificial reef over 7 monitoring years (Figure 5).

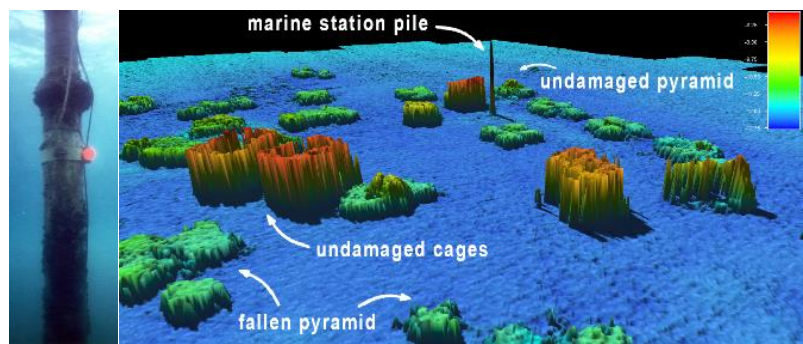

Figure 4. Marine station pile (left) and its 3D model in close-up perspective view of the AR multibeam bathymetry recorded in 2014 (right)

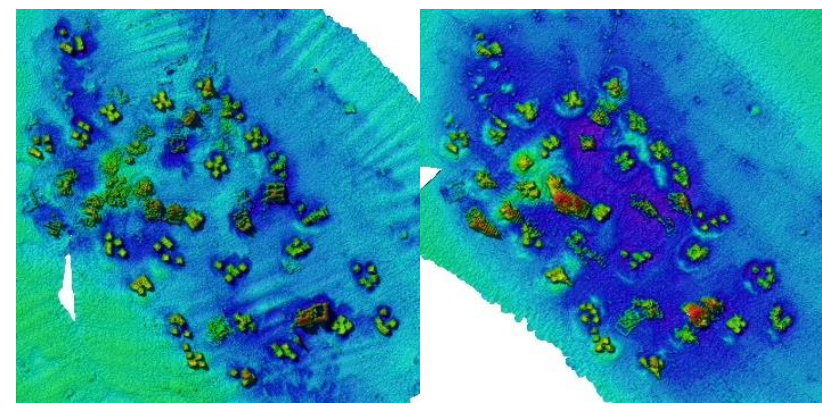
2001 2002

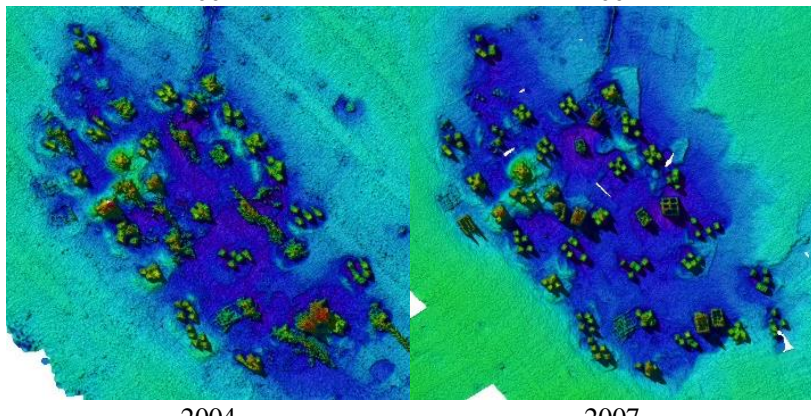

2004

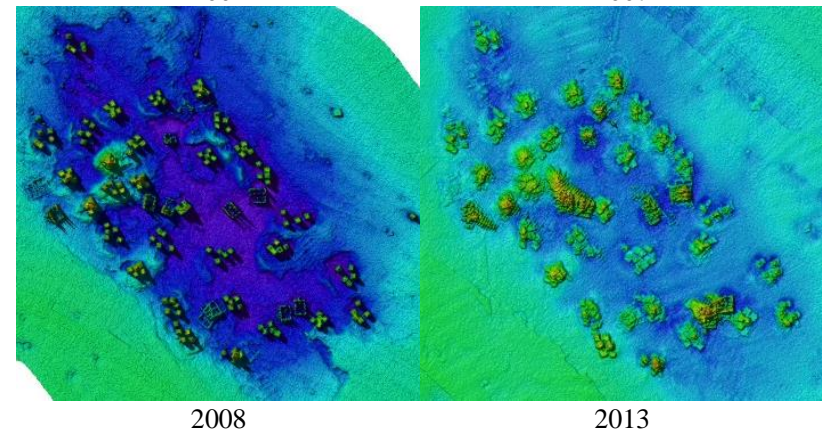

2008

2013

Depth $(\mathrm{m})$

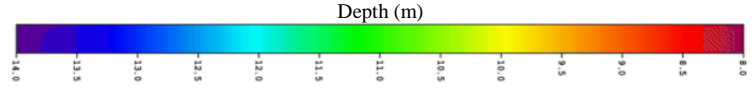

Figure 5. MBES bathymetric maps (25-cm grid) of the Senigallia AR over 6 monitoring years

Last 3D models of the original AR structures are imported to enhance visualization and analysis.

In Figure 6b, a 3D rendering of the original AR structures is superimposed in the MBES sonar data revealing an intuitivelooking depiction of AR spatial arrangement at the time of last survey (July 2014). 


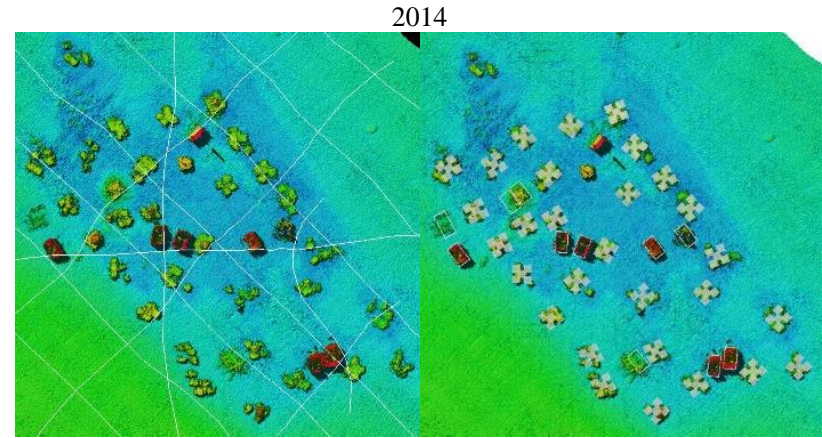

(a)

(b)

Depth (m)

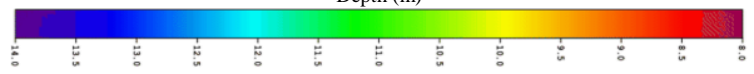

Figure 6. MBES bathymetric map 2014 (15-cm grid) of the

Senigallia AR superimposing ship tracks during the survey (a) and $3 \mathrm{D}$ rendering of the original AR structures (b)

Difference surface were calculated between the surveyed data to make additional volume and depth assessments over monitoring years.

Given the relatively large and 3D spatial coverage of the MBES data, the seafloor depth was determined quantitatively through statistical examinations or drawing out seafloor profiles. Similarly, the depth of the scour pit and/or the top of each AR unit was measured directly through profiling across the scour pit or the AR unit.

Moreover, given the well-known dimensions of the AR units, apart from directly measuring the depth of their top and of the surrounding ambient seafloor, the MBES surveys provided direct estimates of AR units' buried depth and surface areas (to the limits of accuracy of the MBES system).

Figure 7 gives an example of a profile on MBES data set 2014, crossing the seafloor surrounding two concrete blocks, one of them clearly tilted to the profile direction.

The depth of the ambient seafloor is measured at $12.4 \mathrm{~m}$ while the maximum depth of the top of the units is measured to be respectively $11 \mathrm{~m}$ and $11.4 \mathrm{~m}$. Given the AR block dimension of $2 \times 2 \times 2 \mathrm{~m}$, this results in a maximum scour depth of $0.6 \mathrm{~m}$ and 1 $\mathrm{m}$.

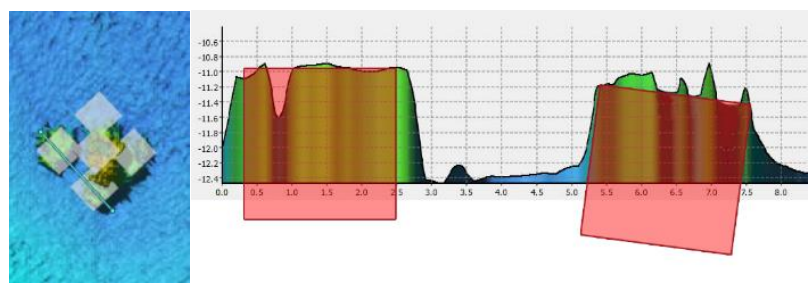

Figure 7. Estimating AR unit burial by measuring cross section on the 3D surface surrounding the blocks. Red areas show approximate shape and dimension of the AR concrete blocks

\section{RESULTS AND DISCUSSION}

The detail and coverage provided by the multibeam sonar, along with the ability to render and visualize the seafloor bathymetry and every single AR structure in 3D, offered several approaches to map the reef and measure the depth/degree of burial of its units at the snapshots in time represented by the MBES surveys.

They allowed to make metric observations on the Senigallia AR interactions with the habitat it is deployed in and on its ecological and physical function across temporal scales during its design life.
Over monitoring years, darker areas around AR units evidenced terrain subsidence, followed by banks of removed substrate (light boundaries in Figures 5 and 6) which appeared lower and lower over monitoring years.

In 2001 most artificial 2-layer pyramids and cages were already not intact (more the $50 \%$ of pyramids and $40 \%$ of cages).

Over the following years, no additional significant collapses were observed while some smaller vertical/horizontal movements of the single units had kept on occurring and scour signatures had been well depicted, indicating reversals of the local current.

To analyse scour formation, bathymetric finite difference grids were generated between subsequent surveyed MBES data.

Since 2001, because of the close arrangement deflecting the instable bottom, a deepening of the whole AR area was clearly visible: with a mean depth of $12.43 \mathrm{~m}$, the seafloor was $1.20 \mathrm{~m}$ deeper than the pre-deployment surface. It was.

Over following seven years (2001-2008) this deepening increased by $30 \mathrm{~cm}$ (in the central AR area) while MBES data 2013-2014 and relative surface differences showed how it has been recently filled in by silt, covering structures with accumulations up to $50 \mathrm{~cm}$.

Figure 8 shows the surface difference created by subtracting the bathymetric grid of the survey 2002 from the bathymetric grid o the final survey. 2014 This resulted in a difference grid showing areas of deposition (positive values, green areas in Figure 8) and erosion (negative values, red areas in Figure 8 ) between the two surveys.

It underlines the predominant mentioned silting up over the whole AR area (bright green areas in Figure 8) with only some erosion windows (red/pink areas in Figure 8) right by AR units spatially closer and deployed along NW-SE direction.

This occurs in conjunction with abundant rains that have incremented, over last 2 years, terrigenous riverine inputs.

The spatial distribution of the silting up areas (in green in Figure 8) suggests how the reef affects the sediment pile up in the surrounding area too.

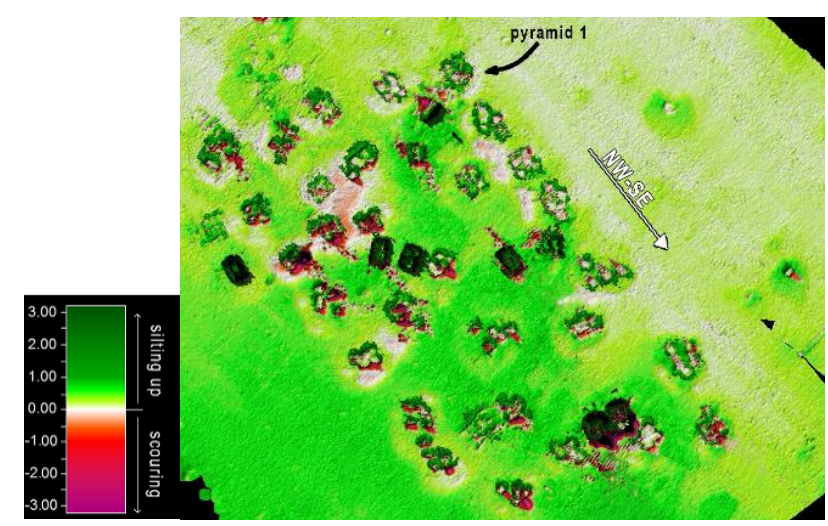

Figure 8. Surface difference between MBES data 2014 and 2002. Pyramid 1 is chosen to draw following corroborating profiles.

In Figure 8 intact cages are mapped by a dark green colour, standing for a positive depth difference of nearly $3 \mathrm{~m}$.

It happens because of different spike filter settings used during the data collection.

At the time of the survey 2002, a medium spike filter was applied to the raw MBES data to decrease the number of erroneous data pings. If a depth measurement for a particular ping fell too far below or above that of surrounding pings, the ping was considered erroneous and was deleted.

It was, therefore, possible that only a few pings hit off the thin concrete cage skeletons as the sonar passed overhead, resulting 
in the pings being determined erroneous by the spike filter and so deleted.

Consistent conclusions can be drawn measuring cross sections on subsequent 3D MBES surfaces surrounding each AR unit.

An example is given in Figure 9, profiling across a selected pyramid (labelled with number 1 in Figure 8) and over chosen monitoring years $(2002,2008$ and 2014).

Figure 9 corroborates the above described first deepening in 2008 (with a depth of the ambient seafloor increased to almost $13 \mathrm{~m}$ ) and the following silting up (MBES data 2014).

Grey shapes in Figure 9 represent true dimensions of the concrete cubes $(2 \mathrm{mx} 2 \mathrm{~m})$ and allow to simulate possible pyramid movements and changes in arrangement.

Over years, Pyramid 1can still be considered undamaged but sunk $30 \%$ or more below the ambient seafloor depth while scour can clearly be seen developing at the sides of the concrete cubes underlying the pyramid.

Buckling along with predominant currents that run parallel to the shoreline in the NW-SE direction, pyramid's movements appear to respond to the predominant wave direction and energy.

The 3D nature of the MBES data also allowed the direct observation of the bulk volume characterizing the reef (Section 3.1 ) and in particular of its more and more gradual decrease over years.

This is due both to the acquired stability of the toppled structures and to the slow silting up.

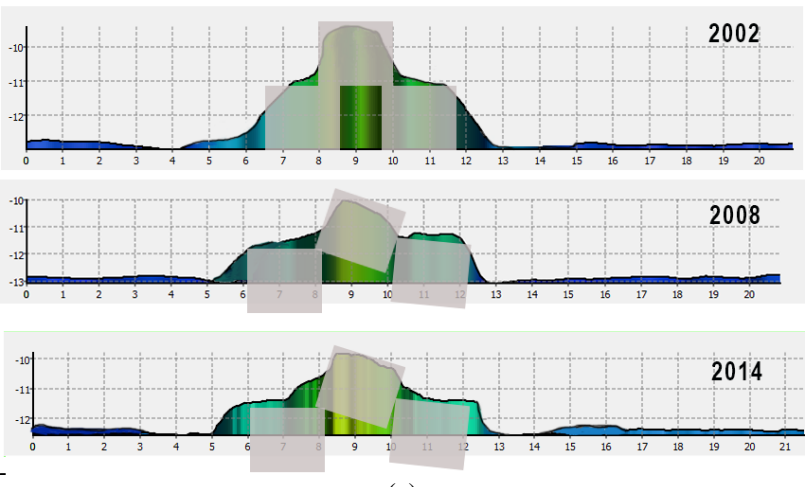

(a)

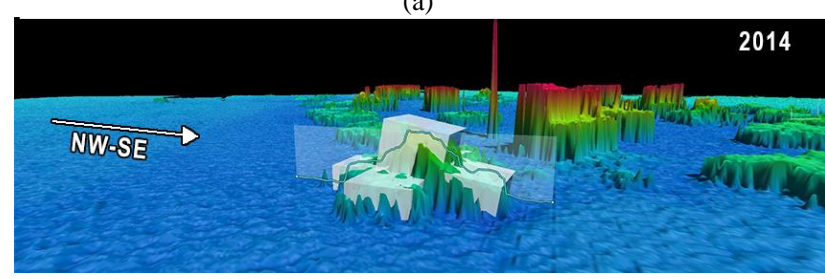

(b)

Figure 9. Progression of AR Pyramid 1 burial/integrity over chosen years (a). Profiles were taken along NW-SE direction (b)

\subsection{Volume assessment}

For the purposes of this paper, bulk volume of the reef was defined as the overall volume within the AR boundaries including the volume of the material and the space enclosed within the external AR structures and the free space between them (Grove et al., 1991). It is given by:

$$
\text { Bulk Volume }=A_{A R} * \bar{H}_{A R}
$$

where $A_{A R}$ is the area of the reef, starting from original deployed $8000 \mathrm{~m}^{2}$ and a bit increasing because of pyramids' collapse, while $\bar{H}_{A R}$ is the mean height of all submerged structures estimated by scuba divers up to 2001 and by MBES surveys in the subsequent years.

Because of scoring and subsidence, more than $50 \%$ of AR structures (mostly pyramids) were already collapsed in 2001 causing a strong bulk volume decrease (Figure 9).

Even though the structural collapse was later less significant, a bulk volume drop is still on going because of a slow silting up. From the reef deployment, the AR bulk volume has been reduced by $35 \%$ (from $34.080 \mathrm{~m}^{3}$ in 1987 to $22088 \mathrm{~m}^{3}$ in 2014) with a mean height decreasing from $4.26 \mathrm{~m}$ to $2.51 \mathrm{~m}$ in 2014 .

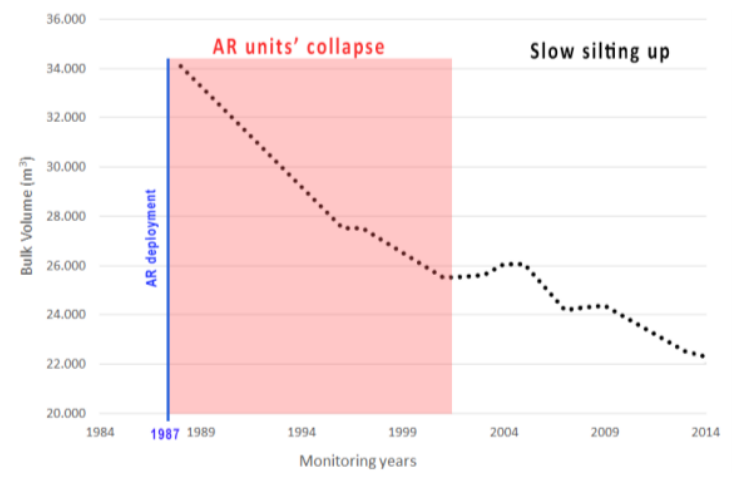

Figure 10. AR bulk volume assessment from AR deployment

\section{CONCLUSIONS}

The resolution of the MBES combined with 3-D visualization techniques provided metric and realistic looking images of AR structures, some of them scoured into local pits but still perfectly identifiable and dimensionally correct.

This required the collection of MBES data with a suitable plan and resolution (both vertical and horizontal).

With an a priori knowledge of the dimensions of AR pyramids and cages, AR units' buried depth and surface areas can be estimated.

Even though the ability to determine morphology changes resulting from significant impacts has been compromised by the lack of pre-deployment MBES data, the 3D nature of the MBES data allowed to map how the reef and the surrounding seafloor quantitatively changed over post-deployment time and directly assess the changes in AR bulk volume.

The results obtained from MBES surveys are confirmed by setnetting methods that are key part of the monitoring plan and are detecting/sampling smaller and smaller assemblages inhabiting the reef (unpublished data).

Further MBES water column surveys are underway in combination with set-netting samplings to evaluate abundance and spatial distribution of fish schools as well as SCUBA diver observations and Remotely Operated Vehicle (ROV) video are planned in order to corroborate the MBES bathymetry data. When combined with other comprehensive field studies and modelling efforts, the multibeam sonar came in handy for providing a unique perspective on the nature of the seafloor surrounding the AR deployment site and new insights into the AR site burial process.

Finally, superimposing 3D rendered models, it was possible to directly visualize the AR state at the snapshot in time during which the surveys took place.

To give an example, in Figure 11 a 3-D rendering of the reef is superimposed in the last MBES data (2014) revealing an intuitive-looking depiction of the state of AR units' burial compared to the original scientifically-planned arrangement. 


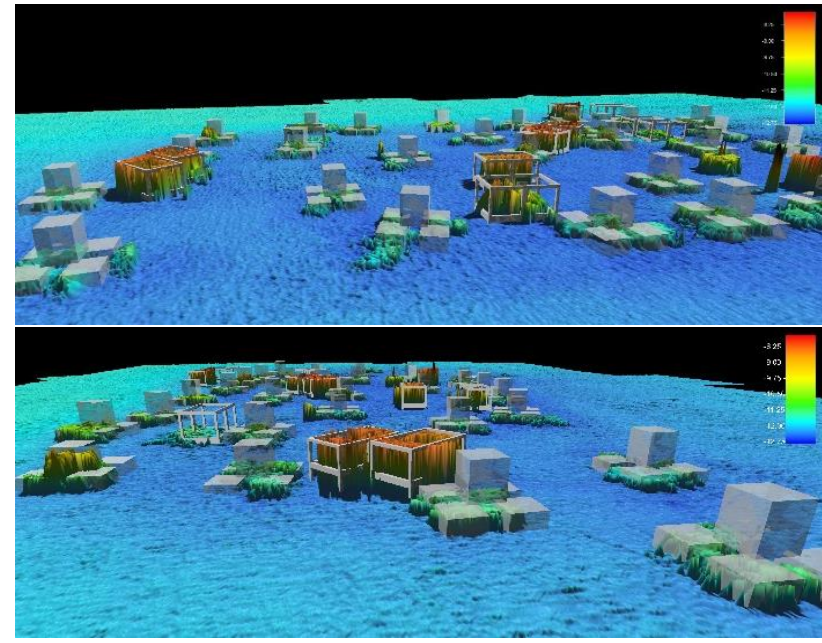

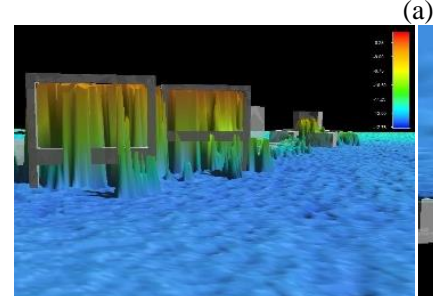

(b)

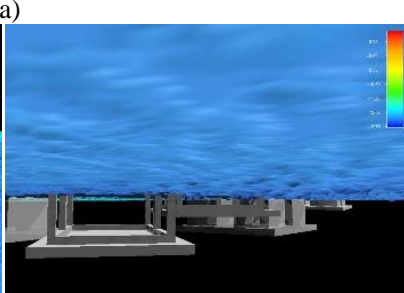

(c)

Figure 11. 3D rendering of AR structures and MBES data set 2014 above $(\mathrm{a}, \mathrm{b})$ and below the seafloor (c)

\section{ACKNOWLEDGEMENTS}

The authors wish to thank Manoukian S. who carried out the Senigallia AR monitoring up to 2008 and the crew of the R/V Tecnopesca II for their help in data acquisition and survey planning.

\section{REFERENCES}

Beyer, A., Rathlau, R., Schenke, H.W., 2005. Multibeam bathymetry of the Håkon Mosby Mud Volcano. Mar. Geophys. Res., 26, pp. 61-75.

Bombace, G., Fabi, G., Fiorentini, L., 2000. Artificial reefs in the Adriatic Sea. In: A.C. Jensen, K.J. Collins, A.P.M. Lockwood (eds.), Artificial reefs in European Seas, Kluwer Academic Publ, Dordrecht, Netherlands, pp. 31-63.

Bombace G., Fabi G., Fiorentini L., Spagnolo A. 1997. Assessment of the ichthyofauna of an artificial reef through visual census and trammel net: comparison between the two sampling techniques. In Hawkins L.E., Hutchinson S. with Jensen A.C., Sheader M., Williams J.A. (eds.): The Responses of Marine Organisms to their Environments - Proceedings of the 30th European Marine Biological Symposium,University of Southampton, Southampton, UK, pp. 291-305.

Bombace G., Fabi G., Fiorentini L. and Speranza S. 1994. Analysis of the efficacy of artificial reefs located in five different areas of Adriatic Sea. Bulletin of Marine Science, 55(2-3), pp. 559-580.

Brown, CJ, Harper, C, 2006. Application of Multibeam: Mapping and monitoring of the Loch Linnhe Artificial Reef complex, Sea Technology, 47(6), pp 31-36.
Chakraborty, B., Mukhopadhyay, R.,Jauhari, P., Mahale, V., Shashikumar, K., Rajesh, M., 2006. Fine-scale analysis of shelfslope physiography across the western continental margin of India. Geo-Mar. Lett., 26, pp. 114-119.

Conway, K.W., Barrie, J.V., Krautter, M., 2005. Geomorphology of unique reefs on the western Canadian shelf: sponge reefs mapped by multibeam bathymetry. Geo-Mar. Lett., 25, pp. 205213.

Fabi, G., Sala, A., 2002. Assessment of biomass and diel activity of fish at an artificial reef (Adriatic sea) using stationary hydroacoustic technique. ICES Journal of Marine Science, 59, pp. 411-420.

Fabi et al. 2014. GFCM Practical Guidelines for Artificial Reefs in the Mediterranean and Black Sea (final draft before editing). http://www.gfcmonline.org/activities/fisheries/artificialreefs/

Grove, R.S., Sonu, C.J., Nakamura, M., 1991. Design and engineering of manufactured habitats for fisheries enhancement. In: Artificial habitats for marine and freshwater fisheries, Seaman, W. Jr., Sprague, L.M. (eds.), Academic Press, Inc, pp. 109-152.

Kovačević, V., Gačić, M., Mazzoldi, A., Dallaporta, G., Gaspari, A., 2000. Seasurface currents measured by coastal HF radar offshore Ancona. Boll. Geofis. Teor. Appl. 41, pp. 339-355.

Knaapen, M.A.F., van Bergen Henegouw, C.N., Hu, Y.Y., 2005. Quantifying bedform migration using multi-beam sonar. GeoMar. Lett., 25, pp. 306-314.

Kenny, A.J., Cato, I., Desprez, M., Fader, G., Schuttenhelm, R.T.E., Side, J., 2003. An overview of seabed-mapping technologies in the context of marine habitat classification. ICES Journal of Marine Science, 60, pp. 411-418.

Lawrence, M.J., Bates, C.R., 2001. Acoustic ground discrimination techniques for submerged archaeological site investigations. Mar. Tech. Soc. J., 35(4), pp. 65-73.

Mayer, L.A., Calder, A.R., Schmidt, J., Malzone, C., 2003. Providing the third dimension: high resolution multibeam sonar as a tool for archaeological investigations - an example from the D-Day beaches of Normandy. U.S. Hydrogr. Conf., Biloxi MS.

Mayer, L.A., 2006. Frontiers in seafloor mapping and visualization. Mar. Geophys. Res., 27, pp. 7-17.

Mayer, L.A., Raymond, R., Glang, G., Richardson, M.D., Traykovski, P., Trembanis, A., 2007. High-resolution mapping of mines and ripples at the Martha's Vineyard Coastal Observatory." IEEEJ. Ocean. Eng., vol. 32, no. 1, pp. 133-149.

Manoukian, S., Fabi, G., Naar, D. F., 2011. Multibeam Investigation of an artificial reef settlement in the Adriatic Sea (Italy) 33 years after its deployment, Brazilian Journal of Oceanography, 59 (Special CARAH Issue), pp. 145-153, ISSN 1982-436X

Manoukian, S., 2011. Impacts of Artificial Reefs on Surrounding Ecosystems. Graduate Theses and Dissertations, College Marine Sci., Univ. South Florida, St., Petersburg, FL.

Paton, M., Mayer, L., Ware, C., 1997. Interactive 3D tools for pipeline route planning. Proc. Oceans'97, pp. 1216-1221. MTS/IEEE, Halifax, NS, Canada. 
Roberts, J.M., Brown, C.J., Long, D., Bates, C.R., 2005. Acoustic mapping using a multibeam echosounder reveals cold-water coral reefs and surrounding habitats. Coral Reefs, 24, pp. 654669.

Ross, S. L., Boore, D. M., Fisher, M. A., Frankel, A. D., Geist, E. L., Hudnut, K. W., Kayen, R. E., Lee, H. J., Normark, W. R., Wong, F. L., 2004. Comments on potential geologic and seismic hazards affecting coastal Ventura County, California: U.S. Geological Survey Open-File Report 2004-1286, 20 pp. [available at http://pubs.usgs.gov/of/2004/1286/].

Sala, A., Fabi, G., Manoukian, S., 2007. Multibeam sonar for mapping and stationary hydroacoustic system for monitoring changes in fish biomass at an artificial reef (Northern Adriatic Sea). Scientia Marina, 71(2), pp. 347-354.

Shyue, S-w., Yang, K-c., 2002. Investigating terrain changes around artificial reefs by using a multi-beam echo sounder. ICES Journal of Marine Science, 59, pp. 338-342.

Shyue, S-w., 1998. Preliminary Study on the Distribution of Artificial Reefs by Using Multibeam Echo Sounder. In: Proceedings of OCEANS '98, October 1998, IEEE/OES, Nice, France, pp. 1144-1148.

Wolfson, M.L., Naar, D.F., Howd, P.A., Locker, S.D., Donahue, B.T., Friedrichs, C.T., Trembanis, A.C., Richardson, M.D., Wever, T.F., 2007. Multibeam observations of mine burial near Clearwater, Florida, including comparisons to predictions of wave induced burial. In: R.H. Wilkens, M.D. Richardson, (Eds.), For a Special Issue on Mine Burial Processes. IEEE Journal of Oceanic Engineering, 32(1), pp. 103-118. 